Original
article

\title{
Association of Kaposi's sarcoma associated herpesvirus (KSHV) DNA in bronchoalveolar lavage fluid of HIV infected individuals with bronchoscopically diagnosed tracheobronchial Kaposi's sarcoma
}

\author{
Mark R Howard, Nicola S Brink, Denise Whitby, Richard S Tedder, Robert F Miller
}

\section{Department of \\ Virology, Division of Pathology and Infectious Diseases, University College London Medical School, University College London Hospitals, London W1P 6DB \\ M R Howard \\ N S Brink \\ R S Tedder}

Department of Sexually Transmitted Diseases, Division of Pathology and Infectious Diseases, University College

London Medical School, Camden \& Islington Community

Health Services Trusts, London WC1 6AU

R F Miller

Virology Laboratory, Institute of Cancer Research, London

SW3 6JB

D Whitby

Correspondence to: Robert F Miller, Department of Sexually Transmitted Diseases, University College London Medical School, Mortimer Market Centre, Mortimer Market, London WC1E 6AU.

Accepted for publication 9 October 1997

Objectives: To determine the frequency of detection of Kaposi's sarcoma associated herpesvirus (KSHV), also known as human herpesvirus (HHV) type 8, DNA in bronchoalveolar lavage (BAL) fluid from HIV infected individuals with and without KS and to compare this with the detection rate in peripheral blood. Also to identify whether KSHV was associated with specific cell types in lavage fluid.

Methods: Nested PCR was used to detect KSHV DNA in BAL fluid from 41 consecutive individuals with Kaposi's sarcoma (KS) and in 41 controls with similar CD4 lymphocyte counts. Semiquantification of viral DNA was by end point titration. A positive cell sorting selection procedure was used to isolate specific BAL fluid cell types.

Results: KSHV DNA was detected in BAL fluid from 24 of 29 (83\%) individuals with a bronchoscopic diagnosis of tracheobronchial KS. None was detected in 12 individuals with only cutaneous KS, or in 41 matched controls without KS. In five, KSHV DNA was detected in the cell depleted and cellular fractions of BAL fluid and in 1/5 in the CD14 (macrophage) fractions. None was detected in the CD19 (B lymphocyte) or CD4/CD8 (T lymphocyte) fractions.

Conclusions: There was a clear association between the diagnosis of tracheobronchial $\mathrm{KS}$ and detection of KSHV DNA in BAL fluid. The cell type supporting KSHV in the respiratory tract is not CD 19 positive and has yet to be conclusively identified.

(Sex Transm Inf 1998;74:27-31)

Keywords: herpesvirus; Kaposi’s sarcoma; lung; macrophages

\section{Introduction}

The presentation of Kaposi's sarcoma (KS) in individuals with AIDS varies from multiple indolent cutaneous tumours to rapidly growing visceral lesions. Within the chest KS may occur in the visceral pleura, mediastinal lymph nodes, lung parenchyma, or the tracheobronchial tree. ${ }^{1-3}$ The diagnosis of KS at bronchoscopy is usually made by visual identification of typical "cherry" red or violaceous lesions within the trachea and bronchi. ${ }^{1-3}$ Bronchial and transbronchial biopsy are rarely performed because of their low diagnostic yield ${ }^{12}$ and the risk of haemorrhage. ${ }^{1}$

Kaposi's sarcoma associated herpesvirus (KSHV) DNA sequences have been identified in KS tumour tissue, ${ }^{45}$ and in peripheral blood mononuclear cells from individuals with $\mathrm{KS}{ }^{6}{ }^{6}$ Recently, serological analysis of a variety of patient groups has also supported an association between $\mathrm{KSHV}$ and $\mathrm{KS} .{ }^{78}$

In a preliminary report we described the detection of KSHV DNA in bronchoalveolar lavage (BAL) fluid and the association of such detection with bronchoscopically determined KS. ${ }^{9}$ In this study we have extended these observations in order to determine the frequency of detection of KSHV DNA in BAL fluid from HIV infected individuals with and without KS. In addition we sought to identify whether KSHV DNA was associated with any specific cell type in BAL fluid.

\section{Materials and methods}

PATIENTS

Eighty two HIV infected individuals admitted to the AIDS unit, University College London Hospitals for investigation of lower respiratory tract disease, were prospectively studied. All patients gave informed consent for bronchoscopy. Forty one consecutive patients (40 males) with cutaneous KS were studied (including 20 previously reported ${ }^{9}$ ). A further $41 \mathrm{HIV}$ infected patients (40 males) with similar CD4 lymphocyte counts and neither cutaneous nor tracheobronchial KS were also studied (including 20 previously studied ${ }^{9}$ ).

All patients had fibreoptic bronchoscopy done by one respiratory physician (RFM) as previously described. ${ }^{10}$ Tracheobronchial KS was diagnosed by visualisation of typical lesions. ${ }^{1-3}$ The bronchoscopic extent was recorded on a proforma, and categorised as localised if lesions were confined to the trachea or the subsegments of one lobe, or widespread if the trachea and one lobe or the subsegments of more than one lobe were affected. ${ }^{3}$ Bronchoalveolar lavage was performed and BAL fluid was processed for storage at $-70^{\circ} \mathrm{C}$ as previously described. ${ }^{10}$ 
DNA AMPLIFICATION

BAL fluid samples were coded and detection of KSHV DNA was done without knowledge of the clinical diagnosis. Amplification by nested polymerase chain reaction (PCR) was used to detect KHSV and human DNA. One $\mathrm{ml}$ of unfractionated BAL fluid was boiled for 10 minutes, centrifuged $(15000 \mathrm{rpm}, 10 \mathrm{~min}$ utes), and the supernatant removed. To screen BAL samples for the presence of KSHV DNA varying amounts of each supernatant $(0.1 \mu \mathrm{l}$, $1 \mu \mathrm{l}, 10 \mu \mathrm{l}$, and $50 \mu \mathrm{l}$ ) were added directly to the first round of PCR mixture consisting of 10 $\mathrm{mM}$ TRIS- $\mathrm{HCl} \mathrm{pH} 8.3,50 \mathrm{mM} \mathrm{MgCl}, 1$ unit of Taq polymerase (Applied Biosystems, London), $200 \mu \mathrm{M}$ of each dNTP, and $100 \mathrm{ng}$ of each outer oligonucleotide primer. These primers were as described. ${ }^{4}$ After an initial denaturation at $94^{\circ} \mathrm{C}, 35$ cycles of amplification comprising 1 minute at $94^{\circ} \mathrm{C}, 1$ minute at $58^{\circ} \mathrm{C}$, and 1 minute at $72^{\circ} \mathrm{C}$ were performed, followed by a 7 minute extension at $72^{\circ} \mathrm{C}$. One $\mu l$ of first round product was transferred to the second round reaction which used inner primers as described. ${ }^{6}$ Thermal cycling for the second round reaction was 25 cycles of $94^{\circ} \mathrm{C}$ for 1 minute, $50^{\circ} \mathrm{C}$ for 1 minute, and $72^{\circ} \mathrm{C}$ for 1 minute. The products of second round PCR amplification were analysed by ethidium bromide agarose gel electrophoresis.

In order to compare the detection rate of KSHV DNA in peripheral blood and BAL between patients with pulmonary plus cutaneous KS and only cutaneous KS heparinised blood samples $(0.5 \mathrm{ml})$ were obtained from 37 patients, 24 of whom had pulmonary and cutaneous KS, seven who had cutaneous KS alone, and six who had no clinical evidence of KS. Blood samples were stored at $-20^{\circ} \mathrm{C}$ in glycigel before DNA extraction. ${ }^{6}$ The median time interval between bronchoscopy and blood sampling was 2 weeks (range 0-36 weeks). KSHV viral load was determined by end point titration in both BAL and heparinised blood.

The single copy human gene encoding pyruvate dehydrogenase was also amplified from BAL fluid samples. This nested PCR for human DNA has previously been shown to have an approximate single copy input sensitivity and in this study was used to determine cellular load in BAL fluid, by use of end point titration. ${ }^{11}$ End point titration to quantify both human and herpesviral DNA levels in clinical samples has been described, and has been shown to be an appropriate and reproducible methodology. ${ }^{11} 12$ The PCR reaction conditions used for human gene amplification were identical to those used for the KSHV nested PCR, as were the reagents. The oligonucleotide sequences of the outer human primers were 5' GGG TAT GGA TGA GGA GCT GGA 3' and 5' TCT TCC ACA GCC CTC GAC TAA 3', and the inner human primers were 5' CTT GGA GAA GAA GTT GCC CAG T $3^{\prime}$ and 5' CCT ACA ATT AAG AGT TGA TCC CTT 3'. As in the nested PCR for $\mathrm{KSHV} 1 \mu \mathrm{l}$ of first round reaction product was transferred to prime the second round reaction.
In order to determine the sensitivity of the KSHV nested PCR, known numbers of the KSHV genome containing HBL-6 cell line, which contains approximately 20-50 KSHV genomes per cell were titrated in a PCR compatible buffer and DNA extracted. The limits of detection of the nested PCR was an input of DNA representing approximately 0.1 HBL-6 cell, equivalent to between two and five KSHV genomes. This level of sensitivity gave an absolute detection sensitivity of approximately 40 copies of KSHV DNA per $\mathrm{ml}$ of BAL fluid and 20 copies of KSHV DNA per ml of heparinised blood.

CELL SEPARATION

In five patients, with tracheobronchial KS, where there was sufficient BAL fluid remaining, $20 \mathrm{ml}$ of whole BAL fluid were centrifuged (15 $000 \mathrm{rpm}, 10$ minutes) and $0.5 \mathrm{ml}$ of the cell free supernatant were ultracentrifuged (100 $000 \mathrm{rpm}, 30$ minutes). DNA was extracted from the pellet obtained by ultracentrifugation of the cell free supernatant using phenol chloroform extraction. From the cells isolated by the initial centrifugation of the whole BAL fluid a positive selection procedure was used to isolate those cells with the cell surface markers CD19, CD4, CD8, and CD14 (MACS, Miltenyi Biotech, Gladbach, Germany). ${ }^{13}{ }^{14}$ Following cell separation DNA from each individual cell type and the remaining unsorted cells (the cell depleted fraction) was isolated by phenol chloroform extraction. All cell fractions from each of the five patients were analysed for the presence of KSHV DNA. Where sufficient extracted material remained the cell numbers (genome equivalents) in each fraction were also measured using pyruvate dehydrogenase human PCR. ${ }^{11}{ }^{12}$

\section{STATISTICAL ANALYSIS}

Detection of KSHV DNA in individuals with and without tracheobronchial KS was compared using a two tailed Fisher's exact test. A p value $<0.05$ was considered significant.

\section{Results}

Of the 82 individuals in this study, 41 had KS; 29 had both tracheobronchial and cutaneous disease and 12 had cutaneous disease only, the diagnosis of $\mathrm{KS}$ was confirmed histologically by bronchial biopsy in one patient (no 12) and at necropsy in five others (nos 1, 4, 13, 14, and 17). Details of the bronchoscopic diagnoses of these 41 patients with individual results of KSHV DNA detection in BAL fluid are given in table 1 .

The bronchoscopic diagnoses in the 41 individuals without pulmonary KS were Pneumocystis carinii pneumonia in 27 , bacterial pneumonia in 10, tracheitis in one, Mycobacterium tuberculosis in two, and $M$ avium-intracellulare with Aspergillus fumigatus in one. Of those 41 individuals without $\mathrm{KS}$ at the time of bronchoscopy three subsequently developed cutaneous KS $(18,26$, and 48 weeks later). Six others died between 1 and 5 (median 4) weeks after bronchoscopy. At necropsy none had Kaposi's sarcoma. Of the remaining 32, 
Table 1 Results of bronchoscopy and KSHV DNA detection in BAL fluid from 41 HIV infected patients with Kaposi's sarcoma $(K S)$

\begin{tabular}{|c|c|c|c|c|c|}
\hline \multirow[b]{2}{*}{ Study No } & \multirow[b]{2}{*}{ Bronchoscopic diagnosis } & \multicolumn{2}{|c|}{ Bronchoscopic extent of $K S$} & \multirow{2}{*}{ 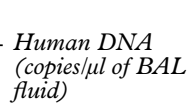 } & \multirow{2}{*}{$\begin{array}{l}\text { KSHV DNA } \\
\text { (copies/1000 cell } \\
\text { genomes in BAL } \\
\text { fluid) }\end{array}$} \\
\hline & & $\begin{array}{l}\text { Widespread/ } \\
\text { localised }\end{array}$ & $\begin{array}{l}\text { No of visible } \\
\text { lesions }\end{array}$ & & \\
\hline \multicolumn{6}{|c|}{ Pulmonary and cutaneous KS: } \\
\hline 1 & PKS & $\mathrm{W}$ & 13 & 100 & 10 \\
\hline 2 & PKS & $\mathrm{L}$ & 2 & 100 & 1 \\
\hline 3 & PKS and $H$ influenzae pneumonia & $\mathrm{W}$ & 18 & 10000 & 1 \\
\hline 4 & $\mathrm{PKS}$ and $\mathrm{PCP}^{\star}$ & $\mathrm{L}$ & 3 & 1000 & 1000 \\
\hline 5 & $\mathrm{PKS}^{\star}$ & $\mathrm{W}$ & 21 & 1000 & 0.2 \\
\hline 6 & PKS & $\mathrm{W}$ & 10 & 1000 & 0.1 \\
\hline 7 & PKS and $P$ aeruginos $a$ pneumonia ${ }^{\star}$ & $\mathrm{W}$ & 14 & 1000 & 0.1 \\
\hline 8 & PKS and $P$ aeruginosa pneumonia & W & 20 & 100 & 10 \\
\hline 9 & $\mathrm{PKS}^{\star}$ & $\mathrm{W}$ & 14 & 1000 & 0.02 \\
\hline 10 & PKS and CMV pneumonitis & $\mathrm{W}$ & 13 & 100 & 0.2 \\
\hline 11 & PKS and $C$ neoformans pneumonia & W & 10 & 1000 & 0.1 \\
\hline 12 & PKS and $C$ neoformans pneumonia & $\mathrm{W}$ & 9 & 10 & ND \\
\hline 13 & PKS and PCP & $\mathrm{W}$ & 20 & 1000 & 1 \\
\hline 14 & PKS and PCP ${ }^{\star}$ & $\mathrm{W}$ & 3 & 1000 & 0.1 \\
\hline 15 & PKS & $\mathrm{W}$ & 5 & 100 & 0.02 \\
\hline 16 & PKS and MAI & W & 2 & 10 & 0.02 \\
\hline 17 & PKS & $\mathrm{W}$ & 8 & 1000 & 1 \\
\hline 18 & PKS and $M$ xenopi & $\mathrm{L}$ & 8 & 100 & ND \\
\hline 19 & PKS & $\mathrm{W}$ & 9 & 100 & 1 \\
\hline 20 & PKS and $P$ aeruginosa pneumonia ${ }^{\star}$ & $\mathrm{W}$ & 10 & 10000 & 1 \\
\hline 21 & PKS & W & 20 & 1000 & 1 \\
\hline 22 & PKS & $\mathrm{W}$ & 28 & 1000 & 10 \\
\hline 23 & PKS & $\mathrm{W}$ & 13 & 1000 & 0.1 \\
\hline 24 & PKS & $\mathrm{W}$ & 9 & 100 & ND \\
\hline 25 & PKS & $\mathrm{W}$ & 32 & 1000 & 1 \\
\hline 26 & PKS and PCP & W & 30 & 10 & ND \\
\hline 27 & PKS & $\mathrm{W}$ & 14 & 1000 & ND \\
\hline 28 & PKS and PCP & $\mathrm{L}$ & 6 & 100 & 1 \\
\hline 29 & PKS & $\mathrm{L}$ & 2 & 10 & 10 \\
\hline \multicolumn{6}{|c|}{ Cutaneous KS: } \\
\hline 30 & Mixed bacteria and $M A I^{\star}$ & None & 0 & 1000 & ND \\
\hline 31 & PCP & None & 0 & 100 & ND \\
\hline 32 & PCP & None & 0 & 1000 & ND \\
\hline 33 & K pneumoniae pneumonia & None & 0 & 1000 & ND \\
\hline 34 & E coli pneumonia & None & 0 & 100 & ND \\
\hline 35 & Paeruginosa pneumonia & None & 0 & 1000 & ND \\
\hline 36 & $S$ pneumoniae pneumonia & None & 0 & 100 & ND \\
\hline 37 & PCP & None & 0 & 100 & ND \\
\hline 38 & PCP & None & 0 & 1000 & ND \\
\hline 39 & Mixed bacteria and $M A I$ & None & 0 & 10000 & ND \\
\hline 40 & Mycobacterium tuberculosis & None & 0 & 100 & ND \\
\hline 41 & Mycobacterium tuberculosis & None & 0 & 100 & ND \\
\hline
\end{tabular}

PKS = pulmonary Kaposi's sarcoma $\mathrm{PCP}=$ Pneumocystis carinii pneumonia $; \mathrm{W}=$ widespread $\mathrm{L}=$ localised, $\mathrm{ND}=$ not detected; $\mathrm{MAI}=$ Myocabacterium avium-intracellulare ${ }^{\star}{ }^{\star}=$ Previously received chemotherapy for cutaneous Kaposi's sarcoma.

followed for a median of 31 weeks (range 10-116 weeks) none developed clinical evidence of cutaneous or pulmonary KS.

The median CD4 lymphocyte counts in those individuals with and without KS were similar, $30 \times 10^{6} / 1$ (range $\left.0-310 \times 10^{6} / 1\right)$ and 30 $\times 10^{6} / 1$ (range $10-330 \times 10^{6} / 1$ ) respectively (normal range 350-2200 $\times 10^{6} / 1$ ).

BAL fluid samples from all 82 individuals contained detectable human genome, indicating the presence of cellular material and the ability to amplify DNA from all BAL samples. The median load of human DNA recovered from the BAL fluid from both pulmonary disease and control groups was the same at 100 copies per $\mu \mathrm{l}$ (range $10-10000$ copies per $\mu \mathrm{l}$ ).
This was considered to be important as KSHV is likely, as with other herpesviruses, to be highly cell associated and discrepant cell loads in BAL fluid, between the two groups, may have affected KSHV DNA detection rates.

KSHV DNA was detected in BAL fluid from $24(83 \%)$ of the 29 patients with both cutaneous and pulmonary KS, but was not detected in BAL fluid from any of the 12 with only cutaneous $\mathrm{KS}$ and no bronchoscopic evidence of pulmonary KS. KSHV DNA was not detected in the BAL fluid from the 41 individuals who had no form of $\mathrm{KS}$ (table 2). The association between detection of KSHV in BAL fluid and a bronchoscopic diagnosis of tracheobronchial KS was found to be highly statistically

Table 2 Detection of KSHV DNA in BAL fluid and peripheral blood of 82 HIV infected people with and without Kaposi sarcoma (KS)

\begin{tabular}{|c|c|c|c|c|}
\hline \multirow[b]{2}{*}{ Patient group } & \multicolumn{2}{|l|}{$B A L$} & \multicolumn{2}{|l|}{ Blood } \\
\hline & $\begin{array}{l}\text { KSHV DNA } \\
\text { detected (\%) }\end{array}$ & $\begin{array}{l}\text { Range (median) } \\
\text { KSHV copies per } 1000 \\
\text { cell genomes }\end{array}$ & $\begin{array}{l}\text { KSHV DNA } \\
\text { detected (\%) }\end{array}$ & $\begin{array}{l}\text { Range (median) } \\
\text { KSHV copies per ml }\end{array}$ \\
\hline \multicolumn{5}{|l|}{$\mathrm{KS}(\mathrm{n}=41)$} \\
\hline Pulmonary and cutaneous KS $(n=29)$ & $24 / 29(83)$ & $0.02-1000(1.0)$ & $17 / 26(65)$ & $40-2 \times 10^{6}(200)$ \\
\hline Cutaneous KS only $(n=12)$ & $0 / 12(0)$ & ND & $5 / 7(71)$ & $40-2 \times 10^{5}(2000)$ \\
\hline No KS $(n=41)$ & $0 / 41(0)$ & ND & $0 / 6(0)$ & ND \\
\hline
\end{tabular}

$\mathrm{ND}=$ not done. 
Table 3 Cell numbers, by human genome equivalents, in positively selected fractions of $B A L$ fluid

\begin{tabular}{llll}
\hline \multirow{4}{*}{ Patient no } & \multicolumn{2}{l}{ Cell fraction $($ copies/ $\mu l)$} \\
\cline { 2 - 4 } & $C D$ 4/8 & $C D 14$ & $C D 19$ \\
\hline 19 & 1 & $100^{\star}$ & 100 \\
21 & ND & 1000 & 10 \\
22 & NS & 100 & 100 \\
\hline
\end{tabular}

$\star$ KSHV DNA detected only in this fraction. ND = not detected, $\mathrm{NS}=$ no sample.

significant, $\mathrm{p}<0.001$. Titres of viral DNA in BAL fluid, as expressed as KSHV DNA copies per 1000 human genomes, varied over a $5 \log _{10}$ range.

Samples of peripheral blood were available from a proportion of patients with pulmonary and cutaneous KS (26 of the 29), cutaneous KS only (seven of the 12) and no KS (six of the 41). KSHV DNA could be detected in the peripheral blood of patients with pulmonary and cutaneous KS (17/26) and in those with cutaneous KS only (5/7) in similar proportions, as shown in table 2 . The median titre and range for both groups are shown in table 2 . For patients with pulmonary and cutaneous KS the median KSHV DNA blood titre was 200 copies per $\mathrm{ml}$ (range $40-2 \times 10^{6}$ copies per $\mathrm{ml}$ ) and for those with cutaneous $\mathrm{KS}$ only the median KSHV DNA blood titre was 2000 copies per $\mathrm{ml}$ (range $40-2 \times 10^{5}$ copies per $\mathrm{ml}$ ). In a small number of individuals with no KS we were unable to detect KSHV DNA in peripheral blood.

KSHV DNA was not detected in CD4/CD8 (T lymphocyte) or CD19 (B lymphocyte) components from BAL fluid of any of the five patients (No 17, 19-22) with cutaneous and pulmonary KS. However, KSHV DNA was detected in the CD14 (macrophage) component in one sample (No 19) and in the cell depleted fractions and the ultracentrifuged pellets of all five samples. There was sufficient material from three of the five patients for genome equivalent cell numbers to be determined in the positively selected fractions (table 3). All but one of the positively selected cell fractions contained human DNA: the CD14 fractions from patients 21 and 22 had similar or higher genome equivalents to the CD14 fraction of patient 19 (the only fraction in which KSHV DNA was detected). Cell DNA recovery from the CD 4/8 fractions was low (table 3 ).

\section{Discussion}

The most striking observation in this study was the clear association between the bronchoscopic finding of tracheobronchial $\mathrm{KS}$ and the presence of KSHV DNA in BAL fluid from HIV infected patients with concurrent pulmonary and cutaneous KS. In contrast, none of those with cutaneous KS only had detectable KSHV DNA in BAL fluid, nor was KSHV DNA detected in 41 who were similarly immunosuppressed but with no evidence of cutaneous or pulmonary KS. These results indicate a potential role for detection of KSHV DNA in BAL fluid as an objective confirmatory test for the visual identification of KS lesions at bronchoscopy.
Five of 29 patients with pulmonary KS had no detectable KSHV DNA in BAL fluid. Possible reasons for the lack of detectable KSHV DNA in these individuals include the extent of pulmonary disease, prior chemotherapy, and the amount of cellular material recovered from BAL fluid influencing viral recovery. The extent of pulmonary disease (as detected by the number of visible lesions at bronchoscopy) did not correlate with the failure to detect KSHV DNA in BAL fluid and none of those without detectable KSHV DNA had prior chemotherapy for KS (table 1). Furthermore, the median copies of human DNA per $\mu$ of BAL fluid (the cellular load) was the same in patients with pulmonary KS with and without detectable KSHV DNA (100 copies/ $\mu$ in both groups). A possible explanation for failure to detect KSHV DNA was apparent in only one person whose BAL fluid was found to be grossly blood stained and therefore was likely to contain high levels of porphyrin compounds which are inhibitory to PCR. ${ }^{15}$

The $5 \log _{10}$ range of KSHV DNA titre per 1000 copies of human genome observed in BAL fluid, taken at the time of diagnosis of pulmonary $\mathrm{KS}$, showed no obvious correlation of with bronchoscopically determined number of pulmonary KS lesions or general pulmonary $\mathrm{KS}$ disease extent.

Our detection of KSHV DNA in the peripheral blood of $65-71 \%$ of patients with $\mathrm{KS}$ extends our earlier findings as to the incidence of blood borne detectable KSHV genome. ${ }^{6}$ Importantly this detection of KSHV DNA at approximately the same incidence in both patients with pulmonary and cutaneous $\mathrm{KS}(65 \%)$ and in those with cutaneous $\mathrm{KS}$ alone $(71 \%)$ would suggest that the different rates of KSHV DNA detection in BAL fluid were not due to blood contamination of BAL fluid at time of sampling nor from leucocytes which have entered into the pulmonary cavity as a result of cell associated immunological activity. Few HIV infected patients without clinical evidence of $\mathrm{KS}$ are expected to have detectable KSHV DNA in their peripheral blood, ${ }^{6}$ therefore it is not surprising that it was not detected in the blood from six without $\mathrm{KS}$ who were tested.

KSHV DNA was not detected in the CD19 lymphocyte component derived from BAL fluid. This contrasts with the finding of $\mathrm{KSHV}$ DNA in peripheral blood B lymphocytes from people with Kaposi's sarcoma. ${ }^{16}$ KSHV DNA was detected in the CD14 (macrophage) component of one BAL sample; the significance of this is uncertain. Recently, KSHV DNA has been detected in the macrophage component of KS lesions. ${ }^{17}$ Whether these cells support viral replication or the detection of KSHV DNA simply reflects their scavenging function is unknown. The failure to amplify KSHV DNA from positively selected fractions would appear not to be due to an insufficient number of recovered cells, as the CD14 cell fractions contained 100 or more genome copies per $\mu 1$ and the CD 19 fractions contained 10 or more copies per $\mu l$. Only the CD 4/8 fractions contained very low levels of human genome. The consistent finding of KSHV DNA in the 
cell depleted pellet of BAL fluid indicates that the major cell type or types that support KSHV replication in the respiratory tract have yet to be identified.

In summary, detection of KSHV DNA in BAL fluid may provide a useful, objective confirmation for diagnosis of pulmonary KS especially in cases where the bronchoscopic presentation is atypical. Results must, however, be interpreted with caution as the absence of detectable KSHV DNA in lavage fluid may not completely exclude the presence of pulmonary $\mathrm{KS}$. Further work is needed to confirm this association and to describe accurately the site of KSHV replication in the lung.

Presented in part: 20th International Herpesvirus Workshop; Groningen, The Netherlands, July-August 1995; 2nd Meeting of UK HIV Physicians British HIV Association (BHIVA); York, UK, April 1996; 1st International Conference of the Mor Kaposi Research Foundation, Budapest, Hungary, August 1996 (abstract P89)

This study was supported by the Department of Virology, University College London Medical School and the Medical Research Council.

We thank Dr P Moore (Division of Epidemiology, School of Public Health, Columbia University, New York, USA) for donation of the HBL-6 cell line and Professors R Weiss (Virology Laboratory, Institute of Cancer Research, London) and IVD Weller (Department of Sexually Transmitted Diseases, University College, London), for their helpful comments.

1 Zibrak JD, Silverstri RC, Costello P, et al. Bronchoscopic and radiographic features of Kaposi's sarcoma involving the respiratory tract. Chest 1986;90:476-9.

2 Meduri GU, Stover DE, Lee M, et al. Pulmonary Kaposi's sarcoma in the acquired immunodeficiency syndrome. Am sarcoma in the acquired
7 Med $1986 ; 81: 11-8$.

3 Pitchenick AE, Fischl MA, Saldana MJ. Kaposi's sarcoma of the tracheobronchial tree. Clinical, bronchoscopic and pathological features. Chest 1985;87:122-4.
4 Chang Y, Cesarman E, Pessin MS, et al. Identification of herpesvirus-like DNA sequences in AIDS-associated Kaposi's sarcoma. Science 1994;266:1965-9.

5 Boshoff C, Whitby D, Hatzioannou T, et al. Kaposi's sarcoma-associated herpesvirus in HIV-negative Kaposi's sarcoma. Lancet 1995;345:1043-4.

6 Whitby D, Howard MR, Tenant-Flowers M, et al. Detection of Kaposi's sarcoma associated herpesvirus in peripheral blood of HIV-infected individuals and progression to Kaposi's sarcoma. Lancet 1995;346:799-802.

7 Kedes DH, Operskalski E, Busch M, et al. The seroepidemiology of human herpesvirus 8 (Kaposi's sarcomaassociated herpesvirus): distribution of infection in KS risk groups and evidence of sexual transmission. Nature Med 1996;2:918-28.

8 Simpson GR, Schulz TF, Whitby D, et al. Prevalence of Kaposi's sarcoma associated herpesvirus infection measured Kaposi's sarcoma associated herpesvirus infection measured by antibodies to recombinant capsid protein and
immunofluorescence antigen. Lancet 1996;348:1133-8.

9 Howard MR, Brink NS, Miller RF, Tedder RS. Association of human herpes virus with pulmonary Kaposi's sarcoma Lancet 1995;346:712.

10 Miller RF, Kocjan G, Buckland J, et al. Sputum induction for diagnosis of pulmonary disease in HIV positive patients. F Infect 1991;23:5-15.

11 Howard MR, Whitby D, Bahadur G, et al. Detection of human herpesvirus 8 DNA in semen from HIV-infected individuals but not healthy semen donors. AIDS 1997;11: F15-19.

12 Spector SA, Merrill R, Wolf D, Dankner WM. Detection of human cytomegalovirus in plasma of AIDS patients during acute visceral disease by DNA amplification. 7 Clin Microacute visceral disease

13 Miltenyi S, Muller W, Weichel W, Radbruch A. High gradient magnetic cell separation with MACS. Cytometry 1990;11:231-8.

14 Semple JW, Allen D, Chang W, Castaldi P, Freedman J. Rapid separation of CD 14+ and CD19+ lymphocyte populations from human peripheral blood by a magnetic activated cell sorter (MACS). Cytometry 1993;14:955-60.

15 Higuchi R. Rapid, efficient extraction for PCR from cells or blood. Amplifications: a forum for PCR users 1989;2:1-3.

16 Moore PS, Kingsley LA, Holmberg SD, et al. Kaposi's sarcoma-associated herpevirus infection prior to onset of Kaposi's sarccoma. AIDS 1996;10:175-80.

17 Blasig C, Zietz C, Neipel F, et al. Inflammatory cells in AIDS-associated Kaposi's sarcoma are productively inAIDS-associated Kaposi's sarcoma are productively inMór Kaposi Research Foundation. Budapest, Hungary, August 1996 (Abstract No 85). 